\title{
Viabilidade econômica para implantação de um biodigestor: uma alternativa para o pequeno produtor rural suinocultor
}

\section{Economic viability of biodigester implantation: an alternative for small swine farmers}

Viabilidad económica para implantación de un biodigestor: una alternativa a los pequeños criadores de cerdos

Cintia Ferreira Anis ${ }^{1}$ Rita Therezinha Rolim Pietramale ${ }^{2}$ Régio Márcio Toesca Gimenes ${ }^{3}$ Vinícius de Oliveira Ribeiro ${ }^{4}$

${ }^{1}$ Mestranda em Agronegócios no Programa de Pós-Graduação em Agronegócios da Universidade Federal da Grande Dourados (UFGD). E-mail: cifanis@yahoo.com.br, Orcid: http://orcid.org/0000-0002-7504-4900

${ }^{2}$ Mestranda no Programa de Pós-Graduação em Zootecnia da Universidade Federal da Grande Dourados (UFGD). E-mail: rolimpiezoo@gmail.com, Orcid: http://orcid.org/0000-0002-5353-0000

${ }^{3}$ Pós-doutor em Finanças Corporativas, doutor em Administração de Empresas e em Engenharia de Produção e Sistemas (Controladoria de Gestão) e mestre em Administração de Empresas pela Faculdade de Economia, Administração e Contabilidade da Universidade de São Paulo (FEA/USP). Especialista em Metodologia do Ensino Superior e em Análise e Planejamento Empresarial. Economista e contador. E-mail: regiomtoesca@gmail.com, Orcid: http://orcid.org/0000-0001-7834-9892

${ }^{4}$ Professor Adjunto da Universidade Estadual de Mato Grosso do Sul (UEMS). Engenheiro Ambiental e Doutor em Saneamento Ambiental e Recursos Hídricos pela Universidade Federal de Mato Grosso do Sul (UFMS). E-mail: viniciusoribeiro@yahoo.com.br, Orcid: http://orcid.org/0000-0001-8045-5221 
Cintia Ferreira ANIS; Rita Therezinha Rolim PIETRAMALE; Régio Márcio Toesca GIMENES; Vinícius de Oliveira RIBEIRO;

Resumo: A produção brasileira de suínos traz retornos positivos ao agronegócio, mesmo com fatores prejudiciais ao meio ambiente que ocorrem devido ao potencial poluidor dessa atividade, em razão do manuseio inadequado do esterco suíno. Reduzir esses impactos requer o uso de sistemas eficientes e sustentáveis de tratamento de resíduos. O objetivo deste estudo foi analisar a viabilidade econômica da implantação de um sistema de biodigestor para o tratamento de resíduos de uma planta de criação de 1.500 porcas, possibilitando a produção de biogás como fonte alternativa de energia elétrica limpa. Para tanto, utilizou-se de pesquisa bibliográfica sobre a temática e do desenvolvimento de cenários possivelmente realísticos. Dois cenários de investimento foram comparados: I) 20\% de patrimônio e 80\% de financiamento; e II) $100 \%$ do patrimônio líquido. Concluiu-se que os investimentos também são sustentáveis e economicamente viáveis nas duas situações, sendo o II o mais vantajoso, que apresentou menor risco com base na TIR, VPN e IL calculadas.

Palavras-chave: biogás; energia sustentável; unidade produtora de leitões.

\begin{abstract}
The Brazilian pig production brings positive returns to agribusiness, even with the environmentally harmful factors that occurs due to the polluting potential of this activity, owing to inadequate handling of swine manure. To reduce such impacts requires the use of efficient and sustainable waste treatment systems. The goal of this study was to analyze the economic viability for the implantation of a biodigester system for treating the waste from a 1.500 sow breeding plant, making it possible to produce biogas as an alternative source of clean electric energy. For this was used bibliographic research about the subject matter and development of real sceneries possible. Two investment sceneries were compared: I) $20 \%$ equity and $80 \%$ financed; and II) $100 \%$ equity. It was conclude that the investments are sustainable and economically viable too, in both situations, with the II being the most advantageous one, which presented lower risk based on calculated IRR, NPV and IL.
\end{abstract}

Keywords: biogas; sustainable energy; piglet production unit.

Resumen: La producción porcina brasileña trae retornos positivos a los agronegocios, mismo con los factores perjudiciales para el medio ambiente que ocurren debido al potencial contaminante de esta actividad, mediante el manejo inadecuado del estiércol porcino. Para reducir tales impactos se requiere el uso de sistemas de tratamiento de residuos eficientes y sostenibles. El objetivo de este estudio fue analizar la viabilidad económica para la implantación de un sistema de biodigestores para el tratamiento de los desechos de una planta de reproducción de 1.500 cerdas. Para este propósito, se utilizó la investigación bibliográfica sobre el tema y el desarrollo de escenarios posiblemente realistas, haciendo posible la producción de biogás como fuente alternativa de energía eléctrica. Se compararon dos escenarios de inversión: I) $20 \%$ de patrimonio y $80 \%$ financiado; y II) $100 \%$ del patrimonio. La conclusión fue que las inversiones son sostenibles y económicamente viables también, en ambas situaciones, siendo el II el más ventajoso, que presentó un menor riesgo basado en la TIR, VPN y IL calculadas.

Palabras clave: biogás; energía sostenible; unidad de producción de lechones. 


\section{INTRODUÇÃO}

A suinocultura possui um papel importante no agronegócio brasileiro, pois contribui à geração de emprego e renda, favorecendo a permanência do homem no campo, além de fornecer alimentos de alto valor nutritivo para o consumo da população. Há expectativas de um aumento significativo na produção e exportação dos próximos anos, devido aos impactos da peste suína no continente asiático, onde se situa a China, o país de maior produção e consumo de carne suína em âmbito mundial.

Contudo, mesmo diante do cenário promissor, a suinocultura desperta a preocupação sob o ponto de vista da sustentabilidade ambiental, principalmente relacionada à elevada quantidade de dejetos suínos gerados, bem como a sua correta destinação ambiental. Desse modo, em contraposição a se tornar um fator de poluição, pelo manejo incorreto dos resíduos, a suinocultura aliada à tecnologia de biodigestão pode transformar-se numa ferramenta de auxílio para um controle ambiental, contribuindo para redução da contaminação do solo e dos corpos de água e para a preservação do ecossistema com a produção de energia renovável e sustentável.

Em face do exposto, o objetivo do presente trabalho foi avaliar a viabilidade econômica da instalação de biodigestor numa propriedade rural de pequeno porte, com uma unidade de produção de leitões desmamados (UPL), com 1.500 matrizes, situada na região de Dourados, Mato Grosso do Sul (MS), avaliando diferentes cenários de financiamento. Para tanto, utilizou-se de pesquisa bibliográfica sobre a temática e do desenvolvimento de cenários possivelmente realísticos. Tais cenários foram criados para que situações de investimentos pudessem ser estudadas e avaliadas.

\section{A ATIVIDADE SUINÍCOLA BRASILEIRA}

A carne suína é a fonte de proteína animal mais consumida em todo o mundo, sendo o Brasil o quarto maior produtor mundial. O Brasil possui um rebanho suíno quantificado em território nacional de 40.332 .553 cabeças (GERVÁSIO, 2017). O Estado de Mato Grosso do Sul é o oitavo maior produtor nacional (COMPANHIA NACIONAL DE ABASTECIMENTO [CONAB], 
2017). De acordo com a CEPEA (2019), o Brasil produziu 3,75 milhões de toneladas e exportou 693 mil toneladas de suínos para mais de 70 países.

Mesmo com esta produtividade e sua representatividade econômica, ela ainda se apresenta como uma atividade de grande potencial poluidor, devido à composição química dos dejetos suínos, principalmente na criação em confinamento, em que se produz uma elevada quantidade de dejetos (AMARAL; MORÉS, 2007). O manejo incorreto dos dejetos, além de gerar danos ao bem-estar social, devido aos odores gerados e à proliferação de vetores de doenças, acarreta a liberação de substâncias, como o metano $\left(\mathrm{CH}_{4}\right)$, gás carbônico $\left(\mathrm{CO}_{2}\right)$ e compostos nitrogenados (amônia, gases de amônio, óxido nitroso e nitrogênio), que resultam na intensificação do efeito estufa (GUIMARÃES, 2016).

Dessa forma, um dos grandes desafios para a cadeia produtiva de suínos é a exigência da sustentabilidade ambiental nas regiões de produção intensiva, pois, de um lado, existe a pressão pelo aumento do nível dos confinamentos e da produtividade e, de outro lado, há a questão ambiental, que incide nos impactos negativos ao meio natural e na produção de gases de efeito estufa, resultando na necessidade de tecnologias capazes de minimizar esses passivos (KUNZ; HIGARASHI; OLIVEIRA, 2005).

Uma alternativa para o tratamento dos dejetos é a digestão anaeróbia que corresponde ao processo de decomposição da matéria orgânica entre as bactérias. Os dejetos provenientes do intestino animal são carregados de bactérias anaeróbias. O tratamento por biodigestores consiste num processo natural e controlado, que ocorre na ausência de oxigênio, em que os micro-organismos anaeróbios degradam a matéria orgânica por fermentação, transformando-a em biogás, composto em sua maior parte do gás metano $\left(\mathrm{CH}_{4}\right)$, e estabilizando os dejetos (KLEINSTEUBER, 2014).

Segundo Weiland (2009) e Oliveira, Souza e Francisco (2017), a produção de biogás através de digestão anaeróbia, por meio de biodigestores, oferece significativas vantagens sobre outras formas de produção de bioenergia. Seu uso tem potencial para reduzir a necessidade de consumo de outras fontes de energias fósseis e não fósseis, além de poder se caracterizar em nova fonte de renda (SANTOS; NARDI JUNIOR, 2013). 
Conforme Oliveira, Souza e Francisco (2017), o biogás produzido a partir de dejetos animais é mais vantajoso na questão fundiária, pois não compete com a produção de alimentos que utiliza grandes áreas de terras disponíveis. Os resíduos oriundos de produção animal são importantes fontes de obtenção da biomassa. Sua utilização em sistemas biointegrados, com finalidade energética, favorece os aspectos econômicos e ambientais energéticos, pois otimiza ganhos econômicos e ambientais (CALZA et al., 2015).

As estimativas do potencial brasileiro de produção de biogás, a partir da fermentação dos dejetos de suínos, mostram a grande importância que pode ocupar na matriz energética do País. Estima-se que cada fêmea e sua prole têm um potencial médio equivalente 1,25 KWh (COLATTO, 2011). Desta forma, uma análise econômica sobre investimentos em tal tecnologia apresenta-se como imprescindível (OLIVEIRA; SOUZA; FRANCISCO, 2017). Neste contexto, diversos autores têm abordado a viabilidade econômica para a instalação de biodigestores (ZANIN; BAGATINI; PESSATTO, 2010; RICARDO et al., 2018; PASINI et al., 2019).

\section{MATERIAIS E MÉTODOS}

\subsection{Tipo de biodigestor}

O biodigestor que melhor se enquadra na propriedade estudada é o de fluxo tubular, também conhecido na literatura como canadense (Figura 1), devido ao baixo custo, à facilidade de implantação e ao fato de as temperaturas médias da região serem mais quentes, ajudando no processo de decomposição anaeróbia (DIAS et al., 2016). 
Figura 1 - Biodigestor modelo canadense

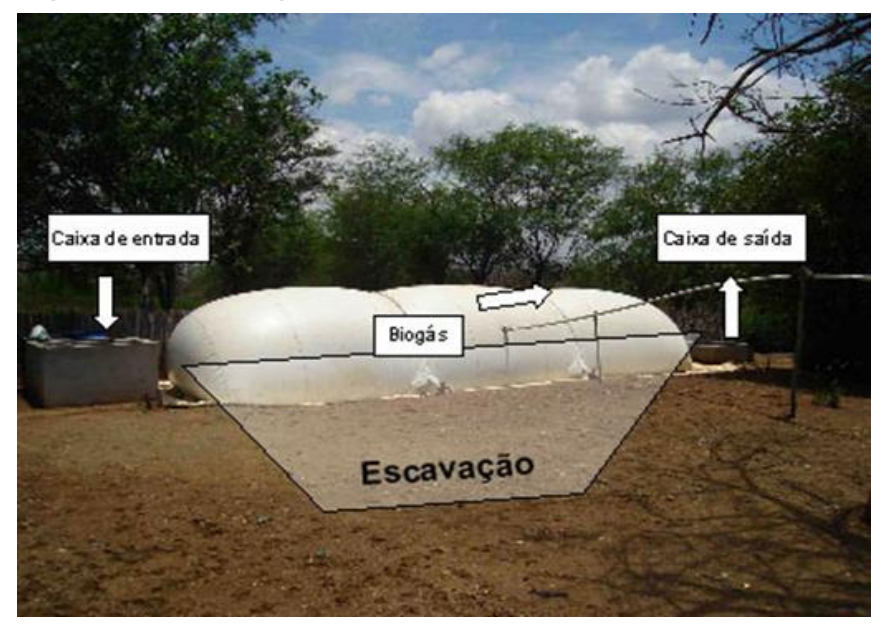

Fonte: Kunz, Higarashi e Oliveira (2005).

O biodigestor de modelo canadense foi desenvolvido pela Marinha Brasileira em 1970 e apresenta uma tecnologia construtiva simplificada. Apresenta uma câmara de digestão escavada no solo e um gasômetro inflável feito de material plástico ou similar e é do tipo horizontal (JUNQUEIRA, 2014).

No biodigestor, os dejetos são canalizados para uma caixa de entrada e destinados a uma câmara de fermentação subterrânea revestida de um material impermeável. O biodigestor, utilizado de forma contínua, é composto principalmente por duas partes: uma câmara fechada, onde ocorre o armazenamento e a digestão da biomassa, e um gasômetro, que serve para armazenar o biogás gerado durante o processo, sendo utilizado de forma contínua (KUNZ; HIGARASHI; OLIVEIRA, 2005).

\subsection{Quadro de investigação}

O estudo abordou a viabilidade econômica de retorno financeiro e risco de investimento para implantação de um biodigestor em uma UPL com 1.500 matrizes, objetivando tratamento dos resíduos e geração de energia com o biogás gerado. Para uma melhor comparação e auxílio na tomada de decisão, as análises foram realizadas a partir do desenvolvimento de dois cenários possivelmente realísticos: 
Viabilidade econômica para implantação de um biodigestor: uma alternativa para o pequeno produtor rural suinocultor

I) Utilizando-se $20 \%$ de capital próprio e $80 \%$ de recurso contratado através de uma linha de crédito do programa $A B C$ do Banco Nacional do Desenvolvimento (BNDES), com uma taxa de juros de 6\% a.a., carência de amortização de 5 anos e prazo para pagamento de 10 anos. O valor adotado de $80 \%$ para ser financiado é o que tem sido concedido em média pelo BNDES aos pequenos produtores, em função do valor de contratação, perfil e score; e

II) O proprietário investindo o valor total com 100\% de capital próprio.

Para análise dos cenários, este trabalho apresenta uma combinação de pesquisa descritiva com uma abordagem quali-quantitativa.

Tais cenários só foram possíveis por meio da busca de informações de campo, através da tomada de conhecimento sobre os investimentos realizados em unidades suinícolas padrão. Esta etapa foi descrita como qualitativa, por partir da observação da realidade e coleta das informações empíricas e técnicas necessárias com suinocultores localizados na região de Dourados, MS. As abordagens destes produtores foram conduzidas informalmente, em que os questionamentos e as conversas versavam sobre custos de aquisição, instalação, capacidade de operação e manutenção de biodigestores.

Para a análise da viabilidade, selecionou-se uma das propriedades investigadas. Isso se deu sob o critério de que o proprietário oportunizou tal estudo dentro da sua atividade. Os dados coletados foram tabulados, gerando os cálculos da viabilidade econômico-financeira do investimento. Obtiveram-se dados em empresas, que solicitaram anonimato, referentes a custos de aquisição e manutenção e dados sobre linhas de financiamento bancário, taxas de juros e condições de empréstimos junto a uma instituição bancária pública, sendo o Banco do Brasil o agente financeiro autorizado a intermediar financiamento com recurso do BNDES.

A parte quantitativa mensurou e determinou os cálculos contábeis e financeiros através de um fluxo de caixa padronizado para aplicação de técnicas de análise de investimentos de capital. As fontes dos dados coletados foram, principalmente, primárias, e o período de coleta foi entre janeiro e fevereiro de 2019. O fluxo de caixa e os cálculos referentes as taxas foram calculados com auxílio da planilha de Excel ${ }^{\circledR}$ e calculadora HP 12 c financeira. 


\section{3 Área de pesquisa}

O estudo foi realizado no sítio Água Boa, localizado na zona rural de Dourados, MS. O município está localizado na região Centro-Oeste do Estado de Mato Grosso do Sul, com 210.218 habitantes (IBGE, 2019), e está entre os 200 mais populosos do Brasil, ocupando a 137ạ posição; é o segundo mais populoso do Estado, com a terceira maior economia (Figura 2), sendo sua principal atividade o agronegócio (IBGE, 2019). A unidade rural possui seis alqueires e tem como atividade principal a produção de leitões desmamados (UPL). A estrutura é composta por instalações que alojam 1.500 matrizes, sendo a atividade a única fonte de renda do produtor.

Figura 2 - Localização de Dourados em Mato Grosso do Sul

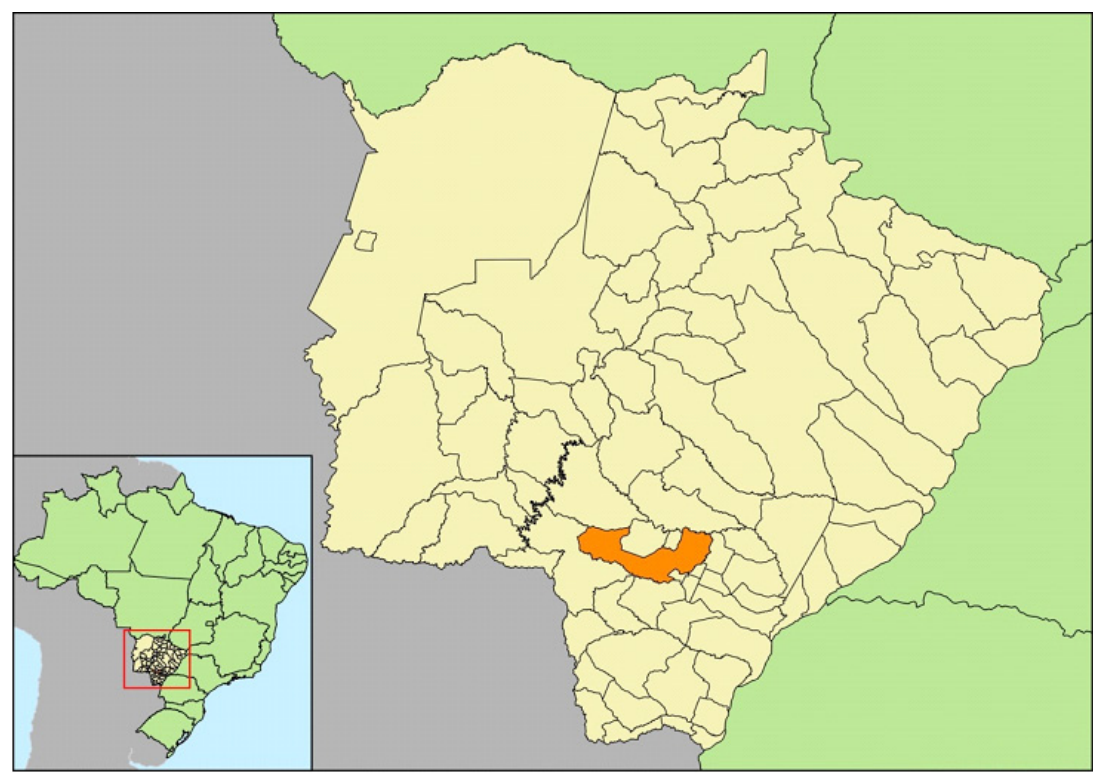

Fonte: Arquivo pessoal.

\subsection{Cálculos para capacidade do biodigestor}

Foram utilizadas as fórmulas mencionadas por Farret (2010), para os cálculos da capacidade de produção de biogás, equação 1 : 


$$
\frac{\tau \text { gás }}{\text { suino }}=Q \frac{\text { dejeto }}{\text { dia }} \times F \frac{\text { produção }}{\text { suino }} \quad \text { (Equação 1) }
$$

Onde:

Tgás/suíno: Total diário de gás produzido por animal;

Qdejeto/dia: Massa de dejetos por animal diária;

Fprodução/suíno: Quantidade de biogás gerado por 1 kg de dejeto.

Os cálculos referentes ao dimensionamento do biodigestor foram adotados a partir da metodologia proposta por Junqueira (2014), equação 2:

Vol.do Biodigestor $\left(\mathrm{m}^{3}\right)=$ Vol. de carga diária $\left(\frac{m^{3}}{\text { dia }}\right) \times$ Tempo de detenção hidráulica (dias)

\section{(Equação 2)}

O tempo de detenção hidráulica é utilizado para calcular a carga volumétrica e assim evitar choques excessivos de carga orgânica, utilizando-se em média 35 dias (OLIVEIRA, 1993).

O cálculo do volume de biogás produzido foi realizado através da relação dejeto/biogás, em que, a cada $1 \mathrm{~kg}$ de dejeto suíno inserido no biodigestor, é gerado 0,35 $\mathrm{m}^{3}$ de biogás, conforme dados do trabalho de Takamatsu e Oliveira (2002). Já para a conversão de biogás em consumo de energia elétrica, considerou-se a equivalência de produção, sendo que cada $1 \mathrm{~m}^{3}$ de biogás é equivalente a 1,25 kWh de eletricidade (TAKAMATSU; OLIVEIRA, 2002).

O processo pode enfrentar redução de capacidade de produção diária de biogás, devido à existência de alguns fatores: falta de conhecimento de manejo por parte dos usuários, areia depositada no fundo da câmara em excesso, intempéries climáticas, entupimento dos tubos, entre outros (KUNZ; HIGARASHI; OLIVEIRA, 2005). Dessa forma, os biodigestores necessitam de manutenção e limpeza diariamente para que sua capacidade possa ser utilizada de forma otimizada.

A receita bruta sobre o custo com energia totaliza o valor que corresponde à economia da taxa de energia elétrica em função da substituição pelo biogás; para tanto, foram utilizadas 12 contas de energia da concessionária 
que realiza o serviço na região, fornecidas pelo produtor. Assim, foi possível traçar a média mensal dos custos com energia elétrica a cada mês. Após a substituição da energia elétrica pelo biogás, esses custos se transformaram em receita no fluxo de caixa do produtor, pela simulação.

Diante deste passivo financeiro, nos cálculos do potencial de geração de biogás e custos de projeto, implantação e operação do sistema, utilizou-se o percentual de capacidade equivalente a 70\%, como margem de segurança, em consonância às estimativas de investimentos de porte e características similares na região.

\subsection{Cálculos financeiros}

Os métodos utilizados nesta pesquisa para avaliar os investimentos são o Fluxo de Caixa, Taxa Interna de Retorno (TIR), Taxa Mínima de Atratividade (TMA), Payback Descontado, Valor Presente Líquido (VPL) e Índice de Lucratividade (IL).

Primeiramente, foi necessário definir o período de investimento; logo após, realizou-se a projeção baseada no: a) investimento inicial, que consiste em todos os gastos incorridos no investimento; b) fluxo de caixa resultante da diferença entre receitas e desembolsos (custos, despesas e impostos); c) custo de depreciação; d) amortização e juros (ASSAF NETO, 2014).

Para a construção do fluxo de caixa do produtor, foram utilizados cálculos compreendendo um período de dez anos (Tabela 1), que representa a vida útil do motogerador de energia elétrica e das lonas utilizadas no sistema de tratamento de dejetos, sendo os bens de maior valor, aos quais foram descontados uma taxa de $10 \%$ ao ano (a.a.) referente à depreciação pelo método linear, obtendo-se o lucro líquido.

O Período de Payback Descontado (DPP) mostra a viabilidade econômica do investimento em unidade de tempo, ou seja, representa o tempo necessário para que o investimento inicial retorne ao investidor, dado seu custo de oportunidade (PUCCINI, 2011). O período de retorno descontado é definido como o número de anos necessário para recuperar o investimento dos fluxos de caixa líquidos descontados, em outras palavras, o valor do dinheiro no tempo (AVACl et al., 2013). 
Para análise da viabilidade de tal investimento, foi necessário a mensuração da Taxa Mínima de Atratividade (TMA), sendo este valor utilizado para descontar o fluxo de caixa de um projeto ou investimento. Assim, o pesquisador pôde identificar métricas contábeis e financeiras, tais como: valor presente líquido (VPL) e taxa interna de retorno (TIR). Além de verificar se o capital investido possui viabilidade econômica, esses cálculos ainda permitem uma visão mais real dos números financeiros (KASSAI; KASSAI; SANTOS, 2000).

Para estimar a TMA, este estudo utilizou o modelo Hybrid Adjusted CAPM (AH-CAPM), equação 3, que ajusta o prêmio do mercado global ao mercado local, usando um país beta que representa matematicamente a inclinação da regressão entre o mercado local e os índices do mercado global. Esse ajuste reduz o efeito de volatilidade dos mercados emergentes, que interfere nos cálculos dos componentes beta e premium do mercado do modelo CAPM original (TEIXEIRA; CUNHA, 2017).

$$
K e=R f g+R c+\beta c l g x[\beta g g x(R m g-R f g)] x\left(1-R^{2}\right) \quad \text { (Equação 3) }
$$

Em que:

Ke = custo de capital próprio;

$\mathrm{Rfg}=$ taxa livre de risco global;

Rc = prêmio de risco país;

$\beta c l g=$ país beta;

$\beta g g$ = beta médio desalavancado de empresas comparáveis cotadas no mercado global;

Rmg = retorno do mercado global;

$\mathrm{R}^{2}=$ Coeficiente de determinação da regressão entre a volatilidade patrimonial do mercado interno e a variação do risco país. 


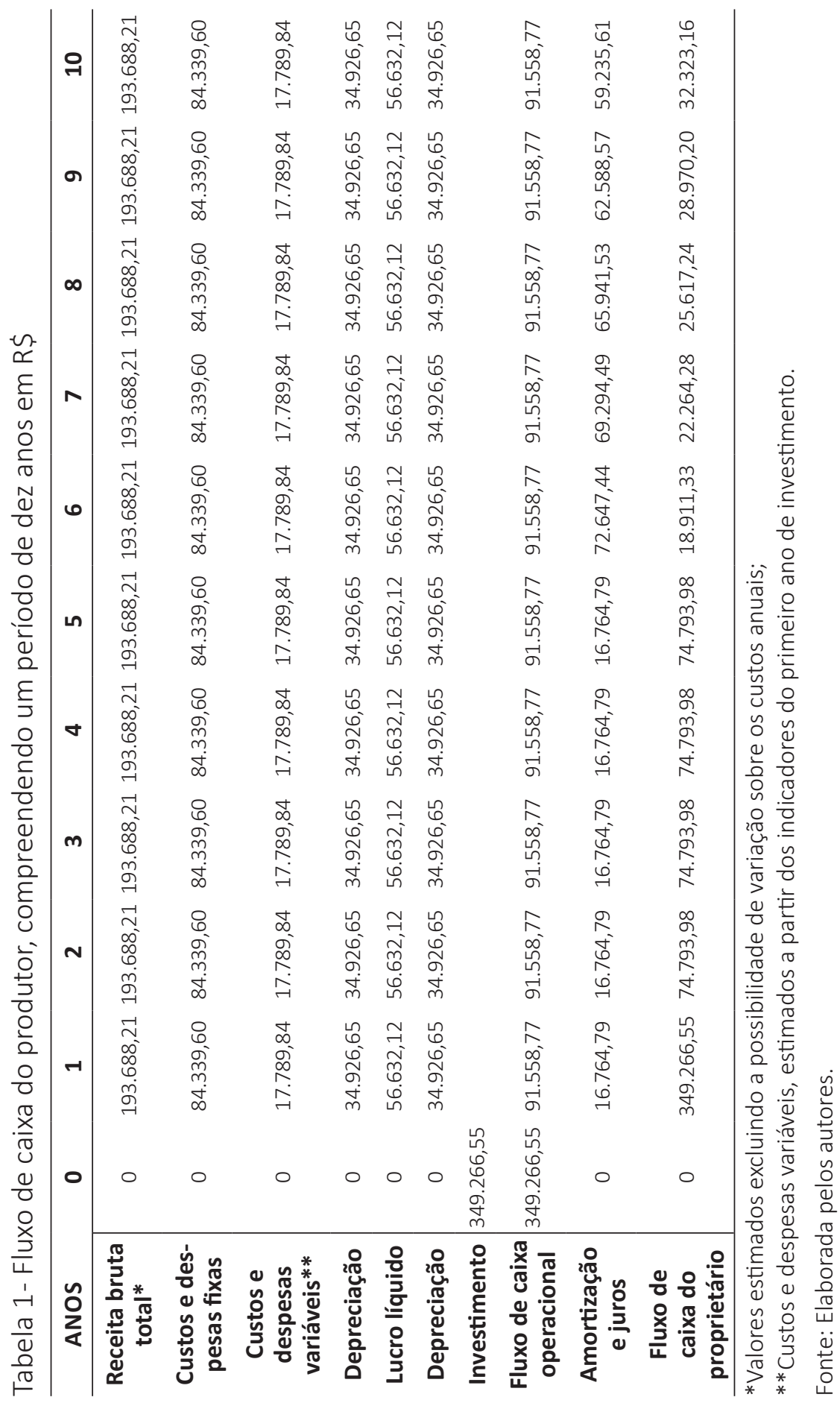


O Valor Presente Líquido (VPL) foi utilizado como uma técnica de orçamento de capital usada para determinar o valor presente de pagamentos futuros descontados a uma taxa apropriada, no caso 9,17\% (GITMAN, 2010).

O VPL, equação 4, é a métrica mais utilizada pelos analistas financeiros e gerentes de empresa para identificar a diferença entre o valor presente das entradas de caixa líquidas e o daquelas associadas ao projeto e ao investimento inicial exigido, com base em uma taxa mínima de atratividade para o investimento. Quando o VPL calculado é positivo, há a indicação de que o projeto é viável na taxa de desconto aplicada; se resultar num valor negativo, o projeto deve ser rejeitado, se for igual a zero, é indiferente a aceitação (AVACl et al., 2013).

O cálculo do valor presente líquido (VPL) resultou na adição de todos os fluxos de caixa na data zero, sendo adotada a seguinte fórmula:

$$
V P L=\sum_{j=1}^{n-1} \frac{f c j}{(1=k) i}+\frac{V R n}{(1+K) n}-\operatorname{Inv}=\sum_{j=0}^{n} \frac{F c j}{(1=k) i}
$$

\section{(Equação 4)}

Em que:

$\mathrm{VPL}=$ valor presente líquido;

$\mathrm{Rj}=$ receitas durante o período $j$;

$\mathrm{C} j=$ custos durante o período $j$;

$\mathrm{i}=$ taxa de desconto;

j = período de ocorrência de Rj e C $\mathrm{j}$.

Já a taxa interna de retorno (TIR) é uma métrica relativa que identifica os ganhos obtidos pelo projeto ao longo do tempo a partir do valor inicial do investimento, com base nos recursos necessários para produzir o fluxo de caixa livre para o investidor (REZENDE; OLIVEIRA, 2001).

A formulação da TIR é representada supondo-se a atualização de todos os fluxos de caixa para o momento zero, equação 5:

$$
\text { Io }+\sum_{t=1}^{n} \frac{l t}{(1+K) t}=\sum_{t=1}^{n} \frac{F C}{(1+K) t}
$$


Em que:

lo = Montante do investimento no momento zero (início do projeto);

$\mathrm{It}=$ Montante previsto de investimento em cada memento subsequente;

$\mathrm{K}=$ Taxa de rentabilidade anual equivalente periódica (TIR);

$\mathrm{FC}=$ Fluxos previstos de entradas de caixa em cada período de vida do projeto (benefícios de caixa).

O Índice de Lucratividade (IL) é um método de avaliação de projetos de investimento, que reduz o problema da escala do investimento por meio da divisão da soma do valor presente dos fluxos de caixa futuros pelo investimento inicial, equação 6.

$$
I L=\sum_{j=1}^{n} \frac{F C j}{\frac{(1+K) j}{h n v}} \quad \text { (Equação 6) }
$$

Em que:

FCj = Fluxo de caixa no período j;

$\mathrm{K}=$ Custo de capital (taxa mínima de atratividade);

$\mathrm{n}$ = Número de períodos analisados;

Inv = Investimento inicial, que corresponde aos fluxos de caixa na data zero.

\section{RESULTADOS E DISCUSSÃO}

\subsection{Custos de instalação e manutenção do biodigestor}

Para que um sistema de tratamento de dejetos via biodigestão seja implantado, são necessários serviços de terraplanagem para montagem do biodigestor; devido à característica do solo irregular no local de instalação, a escavação foi necessária, em decorrência do modelo de biodigestor adotado. Esses custos, acrescidos dos valores de manutenção e operação do sistema de biodigestão, são comuns seja qual for o cenário de fonte de recursos para implantação. 
O valor do investimento a ser realizado para instalação do biodigestor, após projeto e orçamentação com bases em custos correntes e preços praticados por prestadores de serviços e fornecedores de matérias-primas locais, com mês-base de fevereiro de 2019, foi de R\$349.266,55 (Tabela 2).

Tabela 2 - Composição de custos para instalação do biodigestor

\begin{tabular}{c|r}
\hline Discriminação dos investimentos & Custos (R\$) \\
\hline Serviços de terraplanagem e escavação & $70.400,00$ \\
Projeto/execução + anotação de responsabilidade & $37.611,35$ \\
técnica (a.r.t) & $10.104,43$ \\
Serviço técnico & 800,00 \\
Frete & $33.464,09$ \\
Obras civis & $114.549,30$ \\
Lona para biodigestor & $4.218,76$ \\
Tubulação & $6.363,89$ \\
Ferragem da lona para biodigestor & $8.473,28$ \\
Sistema agitador & 464,78 \\
Sistema de controle de pressão & $60.635,79$ \\
Motogerador de energia & $2.180,88$ \\
Abrigo do motor & $\mathbf{3 4 9 . 2 6 6 , 5 5}$ \\
\hline Total
\end{tabular}

Fonte: Elaborada pelos autores.

A Tabela 3 corresponde aos custos estimativos anuais de operação e manutenção do sistema de biodigestão. A operação do sistema de tratamento de dejetos é diária e exige a presença de um funcionário responsável pelo acionamento dos motores, limpeza e zelo das instalações. Dessa forma, o tempo de operação foi estimado em $450 \mathrm{~h}$ /ano e os gastos remuneratórios são de 9,73 h. Assim, o custo da mão de obra necessária para a manutenção, tempo de operação exigido, foi de $\mathrm{R} \$$ 4.376,68 por ano. 
Tabela 3 - Custos operacionais do biodigestor

\begin{tabular}{c|c}
\hline Item & $\begin{array}{c}\text { Custo anual de operação e ma- } \\
\text { nutenção (R\$) }\end{array}$ \\
\hline Óleo lubrificante & $3.357,20$ \\
Filtro de óleo & $1.815,58$ \\
Filtro de gás sulfídrico & $4.664,60$ \\
Filtro de ar & 685,63 \\
Correia dentada e esticador & $2.890,15$ \\
\hline Total & $\mathbf{1 3 . 4 1 3 , 1 6}$ \\
\hline
\end{tabular}

Fonte: Elaborada pelos autores.

\subsection{Avaliação dos cenários de investimento}

Para a análise de uma proposta de investimento, é necessário considerar que o investidor pode estar perdendo o retorno da aplicação do mesmo capital em outro projeto. Assim, é necessário utilizar o cálculo da TMA para auxiliar na tomada de decisão para se investir ou não, observando a taxa de risco e retorno de todas as possibilidades do investimento (CASAROTTO FILHO; KOPITTKE, 2010).

O cálculo da TMA, a partir do método do CAPM - híbrido, resultou em uma taxa anual de 9,17\%. O payback descontado para retorno do investimento foi de 5,08 anos, adotando a TMA de 9,17\%. Esse é o tempo necessário para que o investimento possa dar retorno e esses cálculos estão presentes nos dois cenários analisados.

O risco de qualquer projeto aumenta à medida que o retorno se aproxima do final do horizonte de planejamento. Portanto, quanto mais rápido o investimento retornar, menor será o risco do projeto (SOUZA; CLEMENTE, 2012).

Nessa perspectiva, o investimento no biodigestor é viável, pois o prazo de 5,08 anos para recuperação de todo o capital investido mostra-se relativamente curto em relação ao horizonte de dez anos considerado no fluxo de caixa. 
4.2.1 Cenário I - Investimento com 20\% de capital próprio e $80 \%$ de recurso financiado (BNDES)

No primeiro cenário, o investimento para instalação do biodigestor foi totalmente aplicado no ano zero, totalizando um valor de $\mathrm{R} \$ 349.266,55$, sendo utilizados $20 \%$ de capital próprio e o restante contratado através de uma linha de crédito do programa $A B C$ do Banco Nacional do Desenvolvimento (BNDES), com uma taxa de juros de $6 \%$ ao ano, carência de amortização de 5 anos e prazo para pagamento de 10 anos, conforme tabela 4 a seguir.

Tabela 4 - Empréstimo

\begin{tabular}{c|cccc}
\hline Ano & Saldo devedor (R\$) & Amortização (R\$) & Juros (R\$) & Prestação (R\$) \\
\hline $\mathbf{1}$ & $279.413,24$ & $\mathrm{R} \$ 0,00$ & $\mathrm{R} \$ 16.764,79$ & $\mathrm{R} \$ 16.764,79$ \\
$\mathbf{2}$ & $279.413,24$ & $\mathrm{R} \$ 0,00$ & $\mathrm{R} \$ 16.764,79$ & $\mathrm{R} \$ 16.764,79$ \\
$\mathbf{3}$ & $279.413,24$ & $\mathrm{R} \$ 0,00$ & $\mathrm{R} \$ 16.764,79$ & $\mathrm{R} \$ 16.764,79$ \\
$\mathbf{4}$ & $279.413,24$ & $\mathrm{R} \$ 0,00$ & $\mathrm{R} \$ 16.764,79$ & $\mathrm{R} \$ 16.764,79$ \\
$\mathbf{5}$ & $279.413,24$ & $\mathrm{R} \$ 0,00$ & $\mathrm{R} \$ 16.764,79$ & $\mathrm{R} \$ 16.764,79$ \\
$\mathbf{6}$ & $223.530,59$ & $\mathrm{R} \$ 55.882,65$ & $\mathrm{R} \$ 16.764,79$ & $\mathrm{R} \$ 72.647,44$ \\
$\mathbf{7}$ & $167.647,94$ & $\mathrm{R} \$ 55.882,65$ & $\mathrm{R} \$ 13.411,84$ & $\mathrm{R} \$ 69.294,49$ \\
$\mathbf{8}$ & $111.765,29$ & $\mathrm{R} \$ 55.882,65$ & $\mathrm{R} \$ 10.058,88$ & $\mathrm{R} \$ 65.941,53$ \\
$\mathbf{9}$ & $55.882,64$ & $\mathrm{R} \$ 55.882,65$ & $\mathrm{R} \$ 6.705,92$ & $\mathrm{R} \$ 62.588,57$ \\
$\mathbf{1 0}$ & $-0,01$ & $\mathrm{R} \$ 55.882,65$ & $\mathrm{R} \$ 3.352,96$ & $\mathrm{R} \$ 59.235,61$ \\
\hline
\end{tabular}

Fonte: Elaborada pelos autores.

Nessa situação, o VPL foi de R\$15.397,97, sendo um valor significativamente maior que zero, o que torna viável o investimento.

A TIR calculada resultou em $11,66 \%$, um percentual maior que a TMA de $9,17 \%$, ao compararmos as duas taxas, confirmando-se que na situação apresentada o investimento é viável, a TIR equivale a 2,49\%, maior que a TMA.

Já o índice de lucratividade (IL) resultou em 1,055. Como foi maior que 1 , infere-se que o investimento será recuperado e remunerado na taxa de juros que mede o custo de capital do projeto. Tem-se, portanto, que, a cada $R \$ 1,00$ investido, o retorno será de $R \$ 1,055$. 


\subsubsection{Cenário II - Investimento com 100\% de capital próprio}

No segundo cenário, o produtor investirá 100\% de capital próprio, com o investimento total no ano zero, utilizando a TMA de 9,17\% e o payback descontado de 5,08 anos. Obtêm-se os seguintes resultados:

O VPL foi de $\mathrm{R} \$ 4.447,83$, sendo um valor positivo que corresponde a um projeto viável. Conforme Ferreira (2009), um VPL positivo indica que o projeto de investimento é viável na taxa de desconto aplicada, caso contrário, deve ser rejeitado.

A TIR apresentou o percentual de 9,66\%, sendo maior que a TMA $(9,17 \%)$, indicando também a viabilidade do investimento. De acordo com Kassai, Kassai e Santos (2000), quando a TIR é maior que a TMA utilizada nos fluxos de caixa descontados, o projeto é viável.

O índice de lucratividade (IL) calculado foi de 1,013, sendo que, a cada 1 real investido, obtém-se R\$1,013 de retorno. Conforme Nakagawa (1993), quando o IL é maior que 1, pode-se dizer que o investimento é recuperável de acordo com tempo do payback, será remunerado na taxa de juros que mede o custo de capital do projeto e gerará um lucro extra, na data presente igual ao VPL.

\subsubsection{Seleção do cenário}

Diante do exposto, considerando o período de dez anos e com base nos resultados dos cálculos, pode-se concluir que os dois cenários mostram a viabilidade do investimento estudado para instalação do biodigestor numa pequena propriedade rural.

Contudo o cenário I ( $80 \%$ de financiamento) tem menor risco devido ao resultado da TIR estar bem acima da TMA, apresentando um percentual 2,49\% maior que a TMA. Comparativamente, o VPL apresentou um valor mais significativo em 28,89\% no cenário I.

Embora as condições do financiamento pelo BNDES sejam atrativas devido à taxa de juros reduzida em relação às taxas do mercado (6,5 a 8,5\% a.a.), acrescido do período de carência ( 5 anos), caso possível, é preferível a realização do projeto com investimento em capital próprio. 


\section{CONSIDERAÇÕES FINAIS}

- A atividade suinícola tem sido acusada de ser altamente poluidora. Mas tecnologias cada vez mais viáveis e eficazes são implantadas para reduzir este impacto. Tais inovações trazem sucesso sobre a sustentabilidade econômica e ambiental da atividade. Este sucesso foi expressado nos resultados de ambos os cenários estudados, fazendo com que se conclua que o retorno sobre o investimento é atrativo em ambas as situações ou cenários;

- A alternativa de implementação do biodigestor para tratamento de resíduos de uma granja UPL, com 1.500 matrizes, no município de Dourados, com substituição e complementação de geração de energia elétrica para a pequena propriedade rural, mostrou-se economicamente viável, seja com recursos $100 \%$ próprios ou $80 \%$ financiados;

- O cenário I (com 20\% de capital próprio e $80 \%$ de recurso financiado) mostrou-se viável, com índices de retorno maiores que o da caderneta de poupança, apresentando uma ótima solução para pequenos produtores que não dispõem de todo o valor para o investimento. A linha de crédito oferecida apresenta baixa taxa de juros ( $6 \%$ a.a.) em relação às praticadas no mercado interno e externo (6,5 e 8,5 \% a.a.), além de oferecer um período de carência de 5 anos para o pagamento da amortização;

- O cenário II (100\% capital próprio) apresentou-se mais vantajoso pelo fato de o risco do investimento ser menor, devido aos resultados dos cálculos serem mais significativos, apresentando um rendimento maior, na ordem de $1,055 \%$, sendo superior, por exemplo, ao da caderneta de poupança $(0,3715 \%)$.

- Por fim, espera-se que os resultados deste estudo possam auxiliar na orientação e no apoio aos suinocultores, em especial nas pequenas propriedades rurais no Brasil, pela adoção de sistemas de tratamento de dejetos de maneira ambientalmente e financeiramente sustentáveis, com possibilidade de retorno econômico/financeiro à atividade, que é fundamental para manutenção e geração de emprego e renda no meio rural;

- As afirmações apresentadas neste trabalho asseguram sobre o uso de tecnologias sustentáveis de produção, sendo estas ainda geradoras de renda. Além disso, devido ao Brasil ser um país com uma produção destacável, é possível enfatizar produções cada vez mais eficientes ambientalmente. 


\section{REFERÊNCIAS}

AMARAL, A. L.; MORÉS, N. Planejamento da produção de suínos no esquema 3:1. Suinocultura Industrial, Itu, SP, v. 30, n. 206, p. 12-3, 2007.

ASSAF NETO, A. Valuation: métricas de valor \& avaliação de empresas. São Paulo: Atlas, 2014.

AVACI, A. B.; SOUZA, S. N.; CHAVES, L. I.; NOGUEIRA, C. E.; NIEDZIALKOSKI, R. K.; SECCO, D. Avaliação econômico-financeira da microgeração de energia elétrica proveniente de biogás da suinocultura. Revista Brasileira de Engenharia Agrícola e Ambiental-Agriambi, Campina Grande, PB, v. 17, n. 4, p. 456-62, 2013.

CALZA, L. F.; LIMA, C. B.; NOGUEIRA, C. E. C.; SIQUeIRA, J. A. C.; SANTOS, R. F. Avaliação dos custos de implantação de biodigestores e da energia produzida pelo biogás. Engenharia Agrícola, Jaboticabal, SP, v. 35, n. 6, p. 990-7, nov./dez. 2015.

CASAROTTO FILHO, N.; KOPITTKE, B. H. Análise de investimentos: matemática financeira, engenharia econômica, tomada de decisão, estratégia empresarial. 11. ed. São Paulo: Atlas, 2010.

CENTRO DE ESTUDOS AVANÇADOS EM ECONOMIA APLICADA (CEPEA). Suínos/ CEPEA. Abril 2019. Disponível em: http://www.cepea.esalq.usp.br. Acesso em: 27 jun. 2019.

COLATTO, L.; LANGER, M. Biodigestor - resíduo sólido pecuário para produção de energia. Unoesc \& Ciência-ACET, Joaçaba, SC, v. 2, n. 2, p. 119-28, jul./dez. 2011.

COMPANHIA NACIONAL DE ABASTECIMENTO (CONAB). Análise da carne suína. Dez. 2017. Disponível em: https://www.conab.gov.br/info-agro/analises-do-mercadoagropecuario-e-extrativista/analises-do-mercado/historico-mensal-de-carne-suina/ item/6371-carne-suina-analise-mensal-dezembro-2017. Acesso em: 28 jun. 2019.

DIAS, C. P.; LEITÃO, F. O.; COSER, Fabiano; SILVA, W. H. A suinocultura brasileira e seu potencial de geração de energia elétrica. 2016. Disponível em: http:// www.agricultura.gov.br/assuntos/sustentabilidade/plano-abc/suinocultura-abc/ arquivos-artigos/suinocultura-brasileira-energia.pdf. Acesso em: jun. 2019.

FARRET, F. A. Aproveitamento de pequenas fontes de energia elétrica. 2. ed. Santa Maria, RS: Editora UFSM, 2010. 
Viabilidade econômica para implantação de um biodigestor: uma alternativa para o pequeno produtor rural suinocultor

GERVÁSIO, E. W. Suinocultura paranaense. Curitiba, PR: Secretaria de Estado da Agricultura e do Abastecimento - SEAB, Departamento de Economia Rural, 2017.

GITMAN, L. J. Princípios de administração financeira. 12. ed. São Paulo: Pearson, 2010.

GUIMARÃES, R.; ITO, M. Impactos ambientais da suinocultura: desafios e oportunidades. BNDES Setorial, Brasil, v. 44, p. 125-56, 2016.

INSTITUTO BRASILEIRO DE GEOGRAFIA E ESTATÍSTICA (IBGE). Cidades e Estados. 2019. Disponível em: https://www.ibge.gov.br/cidades-e-estados. Acesso em: 25 ago. 2019.

JUNQUEIRA, S. L. C. D. Geração de energia através de biogás proveniente de esterco bovino: estudo de caso na fazenda aterrado. Rio de Janeiro: Universidade do Rio Janeiro, Departamento de Engenharia Mecânica DEM/POLI/UFRJ, 2014.

KASSAI, J. R.; KASSAI, S.; SANTOS, A. Retorno de investimento: abordagem matemática e contábil do lucro empresarial. 2. ed. São Paulo: Atlas, 2000.

KLEINSTEUBER, S. Special Issue on "Microbial Ecology of Anaerobic Digestion". Bioengineering, v. 1, n. 2, p. 111-2, jun. 2014. Disponível em: https://www.mdpi. com/journal/bioengineering/special_issues/microbial-ecology_of_anaerobic_ digestion. Acesso em: jun. 2019.

KUNZ, A.; HIGARASHI, M.; OLIVEIRA, P. A. Tecnologias de manejo e Tratamento de dejetos de suínos estudados no Brasil. Cadernos de Ciência e Tecnologia, Brasília, DF, v. 22, n. 3, p. 651-65, set./dez. 2005.

NAKAGAWA, M. Introdução à controladoria: conceitos, sistemas e implantação. São Paulo: Atlas, 1993. 104p.

OLIVEIRA, P. A. Manual de manejo e utilização dos dejetos de suínos. Concórdia, SC: EMBRAPA CNPSA, 1993. 188p. (Documentos 27).

OLIVEIRA, L. G.; SOUZA, J. T.; FRANCISCO, A. C. Tratamento de dejetos suínos: oportunidades de conversão em energia. Revista Gestão Industrial, Ponta Grossa, PR, v. 13, n. 3, p. 22-36, set./nov. 2017.

PASINI, F.; PASSINI, A. F. C.; PIOVEZAN, A. A.; CORREA E SILVA, D.; MACHADO, G. A. Viabilidade de implantação de um biodigestor em uma granja de suínos. Holos Environment, Rio Claro, SP, v. 19, n. 1, p. 60-9, 2019. 
PUCCINI, A. L. Matemática financeira: objetiva e aplicada. 9. ed. São Paulo, SP: Elsevier, 2011.

REZENDE, J. L. P.; OLIVEIRA A. D. Análise econômica e social de projetos florestais. Viçosa, MG: UFV, 2001.

RICARDO, C. M.; CAMPOS, A. T.; MARIN, D. B.; VELOSO, A. V.; MATTIOLI, M. C. Avaliação econômica de um sistema de tratamento de resíduos da suinocultura contendo biodigestores tubulares. Revista Engenharia na Agricultura, Viçosa, MG, v. 26, n. 6, p. 516-25, 2018.

SANTOS, E. L. B.; NARDI JUNIOR, G. Produção de biogás a partir de dejetos de origem animal. Tekhne e Logos, Botucatu, SP, v. 4, n. 2, p. 80-90, 2013.

SOUZA, A.; CLEMENTE, A. Decisões Financeiras e análise de investimentos: fundamentos, técnicas e aplicações. 6. ed. São Paulo: Atlas, 2012.

TAKAMATSU, A.; OLIVEIRA, R. F. Manual de biossistemas integrados na suinocultura. Curitiba, PR: TECPAR/CITPAR, 2002.

TEIXEIRA, V. P. M.; CUNHA, M. F. M. Aplicabilidade dos modelos CAPM Local, CAPM Local Ajustado e CAPM Ajustado Híbrido ao Mercado Brasileiro. In: CONGRESSO DE CONTABILIDADE E CONTROLADORIA DA USP, 14., São Paulo, 26-28 jul. 2017. Anais [...]. Disponível em: https://congressousp.fipecafi.org/anais/AnaisCongresso2017/ ArtigosDownload/134.pdf

WEILAND, P. Biogas production: current state and perspectives. Applied Microbiologie and Biotechnologie, Switzerland, AG, v. 85, n. 4, p. 849-60, 2009.

ZANIN, A.; BAGATINI, F. M.; PESSATTO, C. B. Economic and financial viability for the implantation of a biodigester an alternative to reduce the the environmental impacts caused by the swine culture. Revista Custos e Agronegócios on line, v. 6, n. 1, p. 121-39, jan./abr. 2010. 